\title{
Atypical Amniotic Fluid Embolism Managed with a Novel Therapeutic Regimen
}

\author{
Shadi Rezai, ${ }^{1}$ Alexander C. Hughes, ${ }^{2}$ Tracy B. Larsen, ${ }^{3}$ \\ Paul N. Fuller, ${ }^{1}$ and Cassandra E. Henderson ${ }^{4}$ \\ ${ }^{1}$ Department of Obstetrics and Gynecology, Kaiser Permanente Southern California, 1200 Discovery Drive, Bakersfield, \\ Kern County, CA 93309, USA \\ ${ }^{2}$ School of Medicine, St. George's University, St. George's, Grenada \\ ${ }^{3}$ Department of Anesthesiology, Adventist Health Bakersfield, 2615 Chester Avenue, Bakersfield, CA 93301, USA \\ ${ }^{4}$ Department of Obstetrics and Gynecology, Lincoln Medical and Mental Health Center, 234 East 149th Street, Bronx, NY 10451, USA
}

Correspondence should be addressed to Shadi Rezai; rezsha@sgu.edu

and Cassandra E. Henderson; cassandra.henderson@nychhc.org

Received 16 July 2017; Revised 26 September 2017; Accepted 19 November 2017; Published 21 December 2017

Academic Editor: Edi Vaisbuch

Copyright (C) 2017 Shadi Rezai et al. This is an open access article distributed under the Creative Commons Attribution License, which permits unrestricted use, distribution, and reproduction in any medium, provided the original work is properly cited.

\begin{abstract}
Amniotic fluid embolism (AFE) is the second leading cause of maternal mortality in the USA with an incidence of $1: 15,200$ births. The case fatality rate and perinatal mortality associated with AFE are $13-30 \%$ and $9-44 \%$, respectively. This rare but devastating complication can be difficult to diagnose as many of the early signs and symptoms are nonspecific. Compounding this diagnostic challenge is a lack of effective treatment regimens which to date are mostly supportive. We present the case of a 26-year-old woman who suffered from suspected AFE and was successfully treated with the novel regimen of Atropine, Ondansetron, and Ketorolac (AOK). The authors acknowledge that this case does not meet the new criteria proposed, by Clark in 2016, but feel that it is important to share this case report, due to dramatic patient response to the provided supportive therapy presented in this case report. We hope this case report will prompt further research into this novel approach to treating AFE with Atropine, Ondansetron, and Ketorolac.
\end{abstract}

\section{Introduction}

Amniotic fluid embolism (AFE) is a rare, unpredictable, and potentially devastating complication of childbirth, in which amniotic fluid, fetal cells, hair, or other types of debris enter into the maternal pulmonary circulation, causing cardiovascular collapse $[1,2]$. The incidence of AFE ranges from $1: 15,200$ to $1: 53,800$ [3-5]. AFE is the second leading direct cause of maternal death in the USA and Europe [36]. Conde-Agudelo and Romero found the percent total maternal deaths due to AFE to be $13.7 \%$, slightly higher than the previous widely held $10 \%$ [5].

Early recognition and initiation of treatment of AFE are essential to increase the likelihood of patient survival $[1,7]$. This can be a challenge, as AFE is a diagnosis of exclusion with no universal pathological or serological markers $[1,8,9]$. Transesophageal echocardiography (TEE) can be used to determine cardiac dysfunction due to pulmonary hypertension but may not be widely available on obstetric units $[7,10]$. AFE is traditionally diagnosed clinically, in a woman early during labor with ruptured membranes, by a trio of symptoms: acute respiratory distress, cardiovascular collapse, and coagulopathy $[3-5,8,9,11]$. Other symptoms include hypotension, frothing from the mouth, fetal heart rate abnormalities, loss of consciousness, bleeding, uterine atony, and seizure like activity $[8,12]$. However, as a diagnosis of exclusion, the AFE triad is neither sensitive nor specific and should be considered once other diagnoses have been ruled out. Clark has recently proposed diagnostic criteria for AFE case report in order to prevent over reporting, but the Society for Maternal Fetal Medicine (SMFM) continues to support the current clinical diagnosis [11, 13].

With a greater understanding of the pathophysiology of AFE, new therapies have shown potential $[4,5]$. Copper et al. 
have reported "that antiserotonin, antithromboxane, and vagolytic therapy" were the mechanisms for the restoration of a patients' circulation and led to successful resuscitation [14]. We present a similar case of a 26-year-old woman with suspected AFE who was successfully managed with traditional therapy and a novel regimen of Atropine, Ondansetron, and Ketorolac (A-OK) [4, 14].

\section{Case History}

A 26-year-old Hispanic female, G2P1001, at 38 1/7 weeks of gestation complicated by obesity (BMI of 41) and gestational diabetes (GDM2) presented to the emergency room complaining of shortness of breath for approximately 8 hours. On exam she was noted to have a fever (102.2 degrees Fahrenheit or 39.0 degrees Celsius), blood pressure of 119/73 $\mathrm{mm} \mathrm{Hg}$, maternal tachycardia (144 beats per minute (BPM)), tachypnea (24 breaths/minute), oxygen saturation of $97 \%$, and fetal tachycardia (211 BPM). The cervical exam was $1 \mathrm{~cm}$ cervical dilatation, zero percent effacement, long and posterior position fetus in vertex presentation, and intact amniotic fluid membrane (i.e., $1 \mathrm{~cm} /$ long/posterior, vertex, and intact). Urine toxicology screen was negative. Intravenous hydration was initiated and the patient was started on broad spectrum antibiotics for the empirical treatment of sepsis (Piperacillin/Tazobactam, Vancomycin). The patient underwent stat primary low transverse cesarean delivery due to nonreactive tracing and fetal tachycardia with minimal variability (category 2 tracing) under general endotracheal intubation anesthesia with rapid sequence intubation. A total of $200 \mathrm{mg}$ of Propofol with $100 \mathrm{mg}$ of succinylcholine were rapidly infused, and blood pressure at that time was 80/40 mg Hg. A size 7.0 endotracheal tube (ETT) was placed under direct laryngoscopy with clear view of tube passing the vocal cords. Intubation was atraumatic with a grade 1 view. Endotracheal tube was taped and secured at $21 \mathrm{~cm}$. Bilateral breath sounds were obtained by auscultation and positive $\mathrm{CO}_{2}$ per anesthesia monitor were used to confirm placement.

Patient delivered an infant with Apgar of 9 and 9 in one and five minutes, respectively, with meconium amniotic fluid. Immediately after delivery of the infant and before the extraction of placenta, the patient's heart rate remained in 140 beats per minute (BPM), but the patient's oxygen saturation decreased to $72 \%$, blood pressure lowered to $72 / 48 \mathrm{~mm} \mathrm{Hg}$, and end-tidal CO2 (ETCO2) as per the anesthesia monitor fell from 32 to $0 \mathrm{~mm} \mathrm{Hg}$. Normal reference range for ETCO2 is between 35 and $45 \mathrm{~mm} \mathrm{Hg}$. The anesthesia equipment was rapidly checked to confirm that there was no equipment leak or disconnection as the phenylephrine IVP was administered with an initial dose of $200 \mathrm{mcg}$ and repeated several times for a total of $1800 \mathrm{mcg}$ (see Table 1 for summary). The patient was evaluated by the obstetrics team for hysterotomy extensions, lacerations, or uncontrolled bleeding (suggestive of DIC) which was found to be negative.

The anesthesia team initiated A-OK AFE protocol within one minute of onset of the listed symptoms. A-OK consisting of $0.2 \mathrm{mg}$ Atropine, $8 \mathrm{mg}$ Ondansetron, and $15 \mathrm{mg}$ Ketorolac were all given as intravenous push. Within 2-3 minutes the patient's oxygen saturation recovered to $97 \%$ and blood
TABLE 1

Time/dose phenylephrine given

(1) $19: 48: 200 \mathrm{mcg} / \mathrm{ml}$
(2) $20: 00: 200 \mathrm{mcg} / \mathrm{ml}$
(3) $20: 15: 400 \mathrm{mcg} / \mathrm{ml}$
(4) $20: 30: 400 \mathrm{mcg} / \mathrm{ml}$
(5) $20: 45: 400 \mathrm{mcg} / \mathrm{ml}$

Total: $1800 \mathrm{mcg} / \mathrm{ml}$

pressure increased to $138 / 68 \mathrm{~mm} \mathrm{Hg}, \mathrm{CO} 2$ returned per monitor to $32 \mathrm{~mm} \mathrm{Hg}$, but tachycardia remained with a heart rate of approximately 140 BPM (see Figure 2 and Table 2). Patient's oxygen saturation and blood pressure responded to medical management by the anesthesia team with intravenous fluids, Atropine, Ondansetron, and Ketorolac. As the patient responded to medical management, her blood pressures and oxygen saturation quickly improved. To treat uterine atony and intraoperative hemorrhage, the patient received 50 units of Oxytocin and 2 doses of Carboprost, 3 units of packed red blood cells (PRBCs), 1 unit of fresh frozen plasma (FFP), and 3,500 $\mathrm{ml}$ intravenous fluid. She had 2,000 $\mathrm{ml}$ estimated blood loss (EBL).

Once stabilized, she remained intubated and was transported to the intensive care unit (ICU) for further monitoring. Postoperative chest computed tomography (CT) scan with and without contrast did not show any evidence of pulmonary embolism (PE) but showed bibasilar atelectasis with no evidence of definite consolidation and/or pneumonia. Lower extremity Doppler ultrasound showed negative results for deep venous thrombosis (DVT). Intraoperative and postoperative laboratory blood works were also negative for DIC with PT, PTT, and INR within normal limits. Blood culture, urine culture, and sputum cultures were taken and later found to be negative. Chest X-ray was done that showed no acute pathology. Placental pathology was negative for chorioamnionitis, placental abruption, and retroplacental hematoma.

The patient was extubated on postoperative day one. Antibiotics were switched to Cefazolin. The patient remained afebrile and asymptomatic with stable vital signs. The patient and newborn had an uneventful postoperative recovery course and were both discharged on postoperative day 3 with a follow-up appointment at our clinic.

\section{Discussion}

The case described is a woman, with no known risk factors for AFE (summarized in Table 3), presenting to the emergency room in distress with subsequent rapid decomposition after delivery $[17,18]$. The clinical diagnosis of AFE was made and differential diagnoses were ruled out. The patient was managed with traditional cardiovascular support and administration of PRBCs and FFP while the anesthesia team initiated the A-OK therapy. Shortly after A-OK therapy and phenylephrine, the patient experienced a rapid reversal of symptoms and stabilization $[7,19]$. 
TABLE 2: Patient vital signs as demonstrated in Figure 2.

\begin{tabular}{|c|c|c|c|c|c|c|c|}
\hline Event & Time & Minutes & $\mathrm{EtCO}_{2}$ & $\mathrm{RR}$ & $\mathrm{BP}$ & Pulse & $\mathrm{O}_{2}$ saturation \\
\hline \multirow{2}{*}{$\begin{array}{l}\text { Initial patient } \\
\text { presentation to ED }\end{array}$} & $\begin{array}{l}11 / 29 / 16 \\
16: 59: 00\end{array}$ & 0 & \multirow[b]{2}{*}{ NA } & 24 & $119 / 73$ & 144 & $97 \%$ (room air) \\
\hline & $\begin{array}{c}11 / 29 / 2016 \\
19: 15\end{array}$ & 16 & & 21 & $128 / 50$ & 133 & 99\% (room air) \\
\hline $\begin{array}{l}\text { C-section procedure } \\
\text { start }\end{array}$ & $\begin{array}{l}11 / 29 / 16 \\
19: 55: 00\end{array}$ & 56 & 32 & ETT & $128 / 75$ & 120 & $96 \%$ (on ETT) \\
\hline Delivery of baby & $\begin{array}{l}11 / 29 / 16 \\
19: 56: 00 \\
\end{array}$ & 57 & 0 & ETT & $72 / 48$ & 140 & $72 \%$ (on ETT) \\
\hline A-OK therapy initiated & $\begin{array}{l}11 / 29 / 16 \\
19: 57: 00\end{array}$ & 58 & & ETT & $80 / 50$ & 130 & 94\% (on ETT) \\
\hline (Effect of) A-OK therapy & $\begin{array}{l}11 / 29 / 16 \\
20: 00: 00\end{array}$ & 61 & 35 & ETT & $138 / 68$ & 140 & 97\% (on ETT) \\
\hline Operating room timeout & $\begin{array}{l}\text { 11/29/16 } \\
21: 20: 00\end{array}$ & 81 & 37 & 21 & $140 / 94$ & 140 & $94 \%$ (on ventilator) \\
\hline
\end{tabular}

TABLE 3: Risk factors and odd ratios for AFE. Abenhaim et al.

\begin{tabular}{lc}
\hline Risk factors & Odds ratio \\
\hline Placenta previa & 30.4 \\
Preeclampsia & 7.3 \\
Cesarean section & 5.7 \\
Forceps delivery & 4.3 \\
Maternal age > 35 yrs & 2.2 \\
Vacuum delivery & 1.9 \\
All other methods of induction & 1.5 \\
\hline
\end{tabular}

AFE has traditionally been a diagnosis of exclusion made in an emergency situation [11]. Recently, Clark et al. have proposed diagnostic criteria for scientific research but this has not yet been widely adopted $[13,20]$. The Society for Maternal Fetal Medicine (SFMFM) which continues to endorse AFE is a clinical diagnosis with an emphasis on maintaining cardiovascular function and hemodynamic stability [11]. In this case the criteria outlined in Clark et al. 2016 (see Table 4) were not met. The main exclusion criteria, from Clark et al's proposed guidelines, were the presence of fever on admission and during the $\mathrm{C}$ section [13]. Clark et al. suggested that cases with fever should be excluded in order to eliminate infectious causes of cardiovascular collapse seen in sepsis/systemic inflammatory response syndrome (SIRS) [13], but this patient was found to have negative blood cultures and no source of infection. We acknowledge Clark's much needed proposal of universal criteria for reporting research cases but see the limitations of these criteria in clinical practice and case presentations. The authors therefore would like to acknowledge this as an atypical presentation of AFE. This clinical diagnosis is supported by ruling out other likely diagnoses (see Table 5). The rapid return of functional status of pulmonary and cardiovascular systems are congruent with Leighton's findings in 2013 which similarly described the dramatic return of cardiovascular function with the use of A-OK in AFE $[4,14]$. However, adding to the diagnostic uncertainty is the large dose of phenylephrine used in this case. Although not part of the AOK regime phenylephrine the dose used in this case may have contributed to resuscitation and hemodynamic stabilization rather than Atropine, Ondansetron, and Ketorolac.

The current recommendations from the Society for Maternal Fetal Medicine suggest the use of Sildenafil, Dobutamine, Milrinone, inhaled nitrous oxide, Prostacyclin, and Norepinephrine when managing AFE [21]. Sympathomimetic medications help maintain blood pressure, but the mechanism of action of these agents does not address the potential underlying mechanisms of ventricular dysfunction. Historically, studies have suggested mechanical obstruction as the main mechanism for pulmonary hypertension [7]. However, more recent animal models have suggested serotonin and thromboxane act synergistically to cause platelet dysfunction, platelet degranulation, and pulmonary hypertension $[14,21,22]$. According to these models, pulmonary hypertension begins with serotonin stimulation of 5-HT receptors causing pulmonary vasoconstriction [21, 23]. Platelets are entrapped due to the pulmonary vasoconstriction and activated by thromboxane $\left(\mathrm{TXA}_{2}\right)$ [14]. The thromboxane causes the recruitment and activation of additional platelets, compounding pulmonary hypertension with the release of more serotonin mediators causing a self-perpetuating cycle (Figure 1) [4, 14, 21]. Leañios et al. suggested these same mediators, while causing local vasoconstriction, cause systemic vagal stimulation leading to a fall in systemic vasomotor tone [21]. Finally, some animal models have suggested that consumptive coagulopathy occurs due to the activation of platelets, factor III, factor X, and amniotic fluid tissue factor leading to disseminated intravascular coagulation (DIC). However contradictory results have been reported $[5,7,9]$.

Some authors have suggested the ventricular dysfunction is secondary to either pulmonary hypertension caused by serotonin and thromboxane or systemic hypotension caused 
TABLE 4

Proposed criteria for research reporting of amniotic fluid embolism [12]

(1) Sudden onset of cardiorespiratory arrest or both hypotension (systolic blood pressure $<90 \mathrm{~mm} \mathrm{Hg}$ ) and respiratory compromise (dyspnea, cyanosis, or peripheral capillary oxygen saturation $[\mathrm{SpO} 2]<90 \%$ )

(2) Documentation of overt DIC following appearance of these initial signs or symptoms, using scoring system of Scientific and Standardization Committee on DIC of the ISTH, modified for pregnancy Coagulopathy must be detected prior to loss of sufficient blood to itself account for dilutional or shock-related consumptive coagulopathy

(3) Clinical onset during labor or within $30 \mathrm{~min}$ of delivery of placenta

(4) No fever $\left(38.0^{\circ} \mathrm{C}\right)$ during labor

TABLE 5

Differential diagnosis for AFE [5]

Pulmonary thromboembolism; more common later postpartum, chest CT was clear and lower limb Doppler was clear

Anesthetic complications; hypoxia was not associated with administration of any medication

Drug-induced allergic anaphylaxis; no rash or wheeze was observed

Myocardial infarction; no ECG changes and negative troponins

Cardiac arrhythmia; the intraoperative anesthesia record reports sinus tachycardia throughout monitoring

Aspiration of gastric contents; patient was had ETT tube inserted with cuff inflated preventing aspiration

Reaction to local anesthetic drugs; patients' condition deterioration does not correlate with any medications given

Sepsis: sepsis is ruled out since there was no source of infection, and patient had clear chest CT scan with SOB; there were no evidence of pneumonia, blood, and urine cultures which were negative

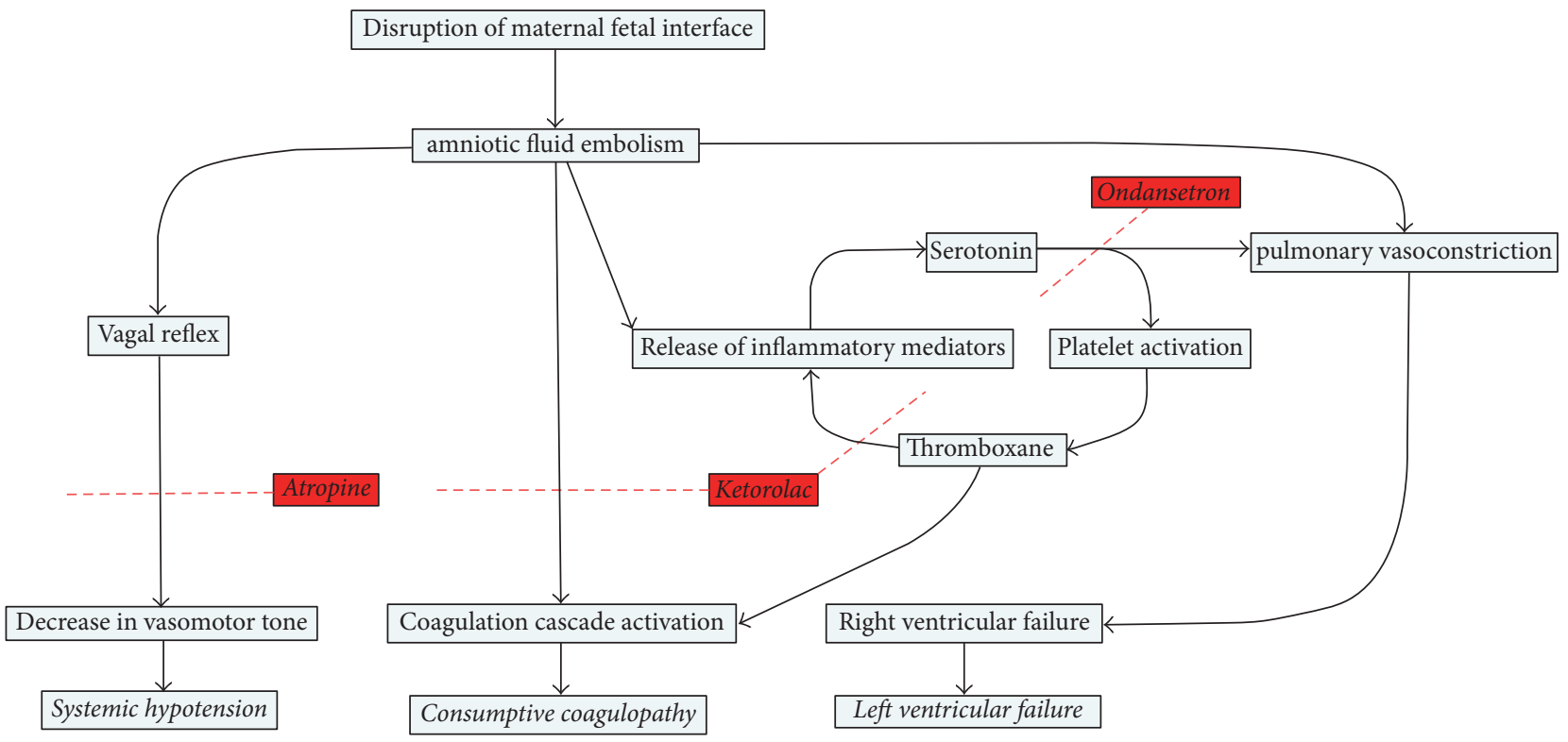

FIGURE 1: Proposed mechanism for Atropine, Ondansetron, and Ketorolac (A-OK) protocol.

by vagal stimulation $[1,11]$. It has been proposed that Atropine and Ondansetron may act to block serotonin and vagal stimulation improving cardiovascular function rather than simply providing cardiovascular support [11]. Additionally, the AOK regimen rather than replacing the consumed factors blocks the proposed cause of coagulopathy by inhibiting thromboxane with Ketorolac $[1,11]$ (see Table 6).

\section{Summary}

Traditionally the prognosis for AFE is poor, with a mortality rate ranging from 13 to $44 \%[1,3]$. Current recommended treatment for AFE includes pulmonary vasodilators, prostaglandins, sympathomimetics, and a host of other interventions $[5,10,15,21]$. Along with these systemic mediators, 


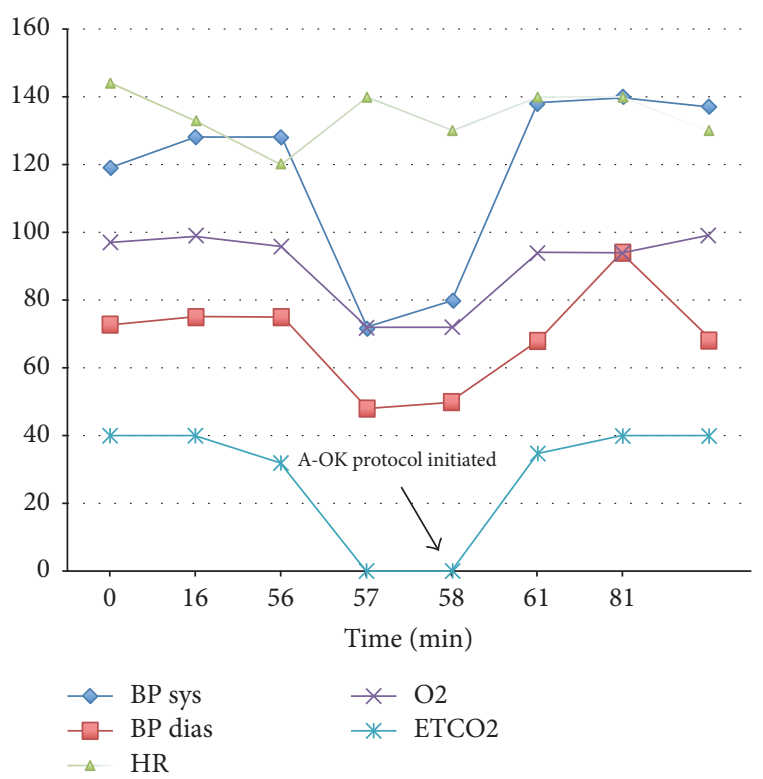

FIGURE 2: Graph of patient's vital signs prior and after initiation of A-OK therapy.

TABLE 6: Shamshirsaz and Clark in SOAP 2013 also describe this A-OK therapy with the addition of metoclopramide, which was not used in our patient [15]. The atropine is used to treat vagal overstimulation and improve vasomotor tone while Ondansetron blocks serotonin receptors inhibiting the release of further mediators $[4,16]$. The Ketorolac blocks thromboxane production thereby preventing coagulopathy [4].

\begin{tabular}{l}
\hline A-OK medication regimen [3] \\
\hline Atropine $1 \mathrm{mg}$ (vagolytic) \\
Ondansetron $8 \mathrm{mg}$ (5-HT3 antagonist) \\
Ketorolac $30 \mathrm{mg}$ (cyclooxygenase inhibitor) \\
\hline
\end{tabular}

large amounts of blood products such as FFP and PRBC are rapidly infused to combat DIC [1]. Other management methods such as bypass and exchange transfusion, by cardiovascular surgery, have also been reported in several cases [10, 16, 24-27].

The authors acknowledge that this case does not meet Clark's proposed criteria for AFE [12]. With AFE affecting many women across the globe and being a significant contributor to maternal mortality, efforts should be made to find effective treatments. We hope this case will prompt future investigation into novel treatments such as A-OK, which can be used in conjunction with traditional supportive measures.

\section{Conflicts of Interest}

The authors did not report any potential conflicts of interest.

\section{Acknowledgments}

The authors would like to thank Ms. Judith Wilkinson, Medical Librarian at Lincoln Medical and Mental Health Center Science Library, for providing the reference articles.

\section{References}

[1] C. S. Sundin and L. B. Mazac, "Amniotic fluid embolism," MCN, The American Journal of Maternal/Child Nursing, vol. 42, no. 1, pp. 29-35, 2017.

[2] K. Kaur, M. Bhardwaj, P. Kumar, S. Singhal, T. Singh, and S. Hooda, "Amniotic fluid embolism," Journal of Anaesthesiology Clinical Pharmacology, vol. 32, no. 2, p. 153, 2016.

[3] C. Thongrong, P. Kasemsiri, J. Hofmann et al., "Amniotic fluid embolism," International Journal of Critical Illness \& Injury Science, vol. 3, no. 1, p. 51, 2013.

[4] B. L. Leighton, "Amniotic Fluid Embolism, March of Dimes," 2013, http://www.marchofdimes.org/pdf/missouri/AFE_11-2113.pdf.

[5] A. Conde-Agudelo and R. Romero, "Amniotic fluid embolism: an evidence-based review," American Journal of Obstetrics \& Gynecology, vol. 201, no. 5, pp. 445.el-445.el3, 2009.

[6] N. McDonnell, M. Knight, M. J. Peek et al., "Amniotic fluid embolism: an Australian-New Zealand population-based study," BMC Pregnancy and Childbirth, vol. 15, no. 1, 2015.

[7] L. S. Dean, R. P. Rogers, R. A. Harley, and D. D. Hood, "Case Scenario," Anesthesiology, vol. 116, no. 1, pp. 186-192, 2012.

[8] S. L. Clark, "Amniotic fluid embolism," Obstetrics \& Gynecology, vol. 123, no. 2, Part 1, pp. 337-348, 2014.

[9] S. L. Clark, F. J. Montz, and J. P. Phelan, "Hemodynamic alterations associated with amniotic fluid embolism: a reappraisal," American Journal of Obstetrics \& Gynecology, vol. 151, no. 5, pp. 617-621, 1985.

[10] B. K. Ray, M. C. Vallejo, M. D. Creinin et al., "Amniotic fluid embolism with second trimester pregnancy termination: a case report," Canadian Journal of Anesthesia, vol. 51, no. 2, Article ID 1482654637, pp. 139-144, Feb 2004, http://download.springer .com/static/pdf/879/art\%253A10.1007\%252FBF03018773.pdf.

[11] L. D. Pacheco, G. Saade, G. D. Hankins, and S. L. Clark, "Amniotic fluid embolism: diagnosis and management," American Journal of Obstetrics \& Gynecology, vol. 215, no. 2, pp. B16-B24, 2016.

[12] S. L. Clark, "Amniotic fluid embolism," Clinical Obstetrics and Gynecology, vol. 53, no. 2, pp. 322-328, 2010.

[13] S. L. Clark, R. Romero, G. A. Dildy et al., "Proposed diagnostic criteria for the case definition of amniotic fluid embolism in research studies," American Journal of Obstetrics \& Gynecology, vol. 215, no. 4, pp. 408-412, 2016.

[14] P. L. Copper, M. P. Otto, and B. L. Leighton, "Successful management of cardiac arrest from amniotic fluid embolism with ondansetron, metoclopramide, atropine, and ketorolac: a case report," SOAP 2013, 2013.

[15] A. A. Shamshirsaz and S. L. Clark, "Amniotic fluid embolism," Obstetrics and Gynecology Clinics of North America, vol. 43, no. 4, pp. 779-790, 2016.

[16] P. Sultan, K. Seligman, and B. Carvalho, "Amniotic fluid embolism," Current Opinion in Anaesthesiology, vol. 29, no. 3, pp. 288-296, 2016.

[17] H. A. Abenhaim, L. Azoulay, M. S. Kramer, and L. Leduc, "Incidence and risk factors of amniotic fluid embolisms: a population-based study on 3 million births in the United States," American Journal of Obstetrics \& Gynecology, vol. 199, no. 1, pp. 49-e8, 2008.

[18] M. Knight, C. Berg, P. Brocklehurst et al., "Amniotic fluid embolism incidence, risk factors and outcomes: a review and recommendations," BMC Pregnancy and Childbirth, vol. 12, no. $1,2012$. 
[19] A. Rafael and M. Benson, "Amniotic fluid embolism: then and now," Obstetric Medicine: The Medicine of Pregnancy, vol. 7, no. 1, pp. 34-36, 2014.

[20] O. Erez, "Proposed diagnostic criteria for the case definition of amniotic fluid embolism in research studies," American Journal of Obstetrics \& Gynecology, vol. 217, no. 2, pp. 228-229, 2017.

[21] O. Leañios, E. Hong, and J. Amezcua, "Reflex circulatory collapse following intrapulmonary entrapment of activated platelets: mediation via 5-HT3 receptor stimulation," British Journal of Pharmacology, vol. 116, no. 3, pp. 2048-2052, 1995.

[22] D. Armstrong and S. Miller, "The role of platelets in the reflex tachypnoeic response to miliary pulmonary embolism in anaesthetized rabbits," Experimental Physiology, vol. 75, no. 6, pp. 791-800, 1990.

[23] X. Jiang, L. Yuan, P. Li et al., "Effect of Simvastatin on 5-HT and 5-HTT in a rat model of pulmonary artery hypertension," Cellular Physiology and Biochemistry, vol. 37, no. 5, pp. 17121724, 2015.

[24] Y. Todo, N. Tamura, H. Itoh, T. Ikeda, and N. Kanayama, "Therapeutic application of $\mathrm{Cl}$ esterase inhibitor concentrate for clinical amniotic fluid embolism: a case report," Clinical Case Reports, vol. 3, no. 7, pp. 673-675, 2015.

[25] E. M. Wise, R. Harika, and F. Zahir, "Successful recovery after amniotic fluid embolism in a patient undergoing vacuumassisted vaginal delivery," Journal of Clinical Anesthesia, vol. 34, pp. 557-561, 2016.

[26] S. L. Clark, G. D. Hankins, D. A. Dudley, G. A. Dildy, and T. Porter, "Amniotic fluid embolism: analysis of the national registry," American Journal of Obstetrics \& Gynecology, vol. 172, no. 4, pp. 1158-1169, 1995.

[27] S. Yufune, M. Tanaka, R. Akai et al., "Successful resuscitation of amniotic fluid embolism applying a new classification and management strategy," Journal of Anesthesia, Clinical Reports, vol. 1, no. 1, 2015. 


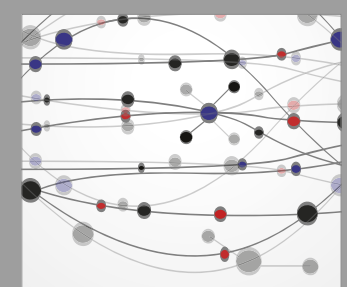

The Scientific World Journal
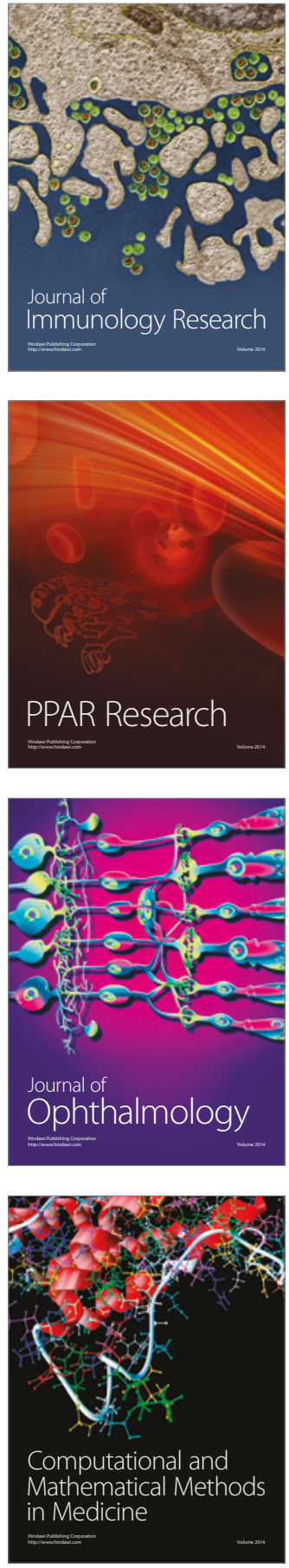

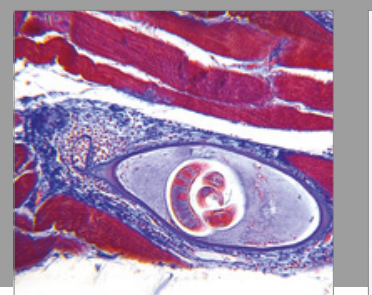

Gastroenterology Research and Practice
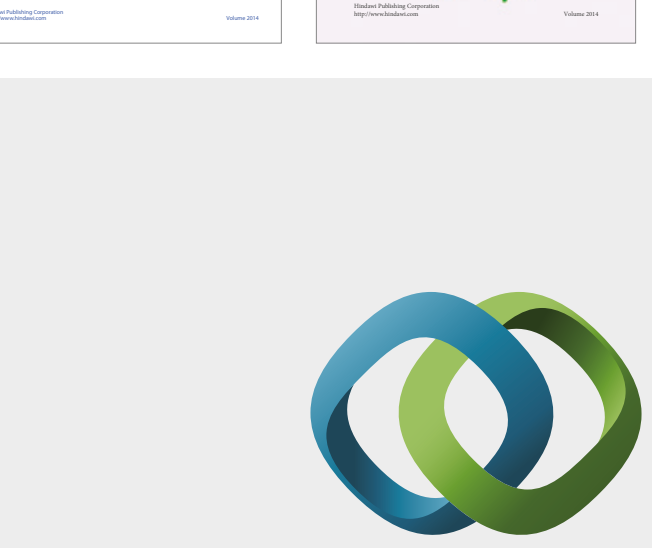

\section{Hindawi}

Submit your manuscripts at

https://www.hindawi.com
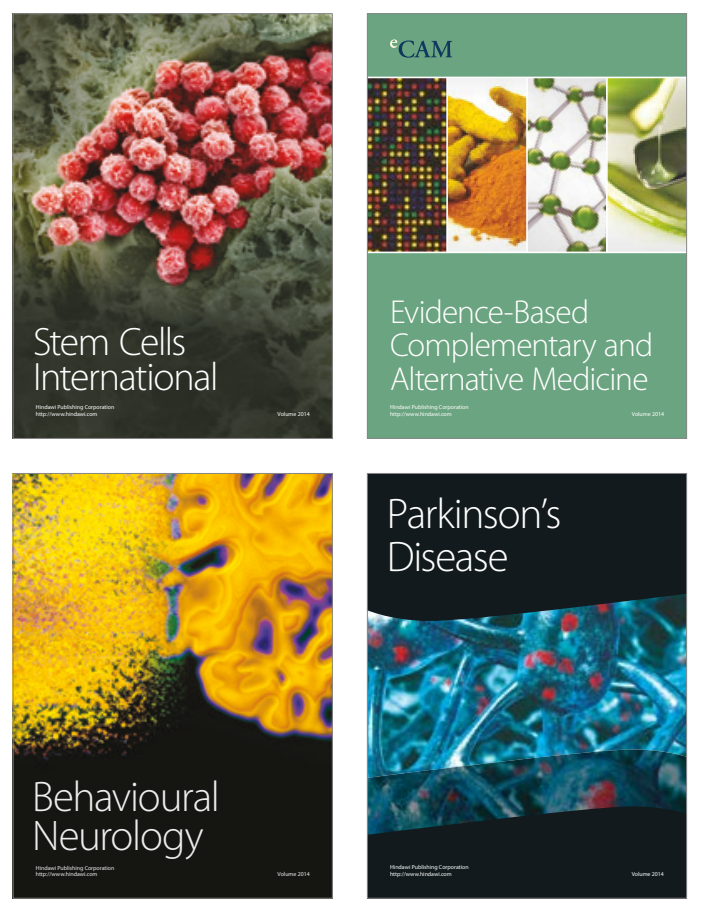
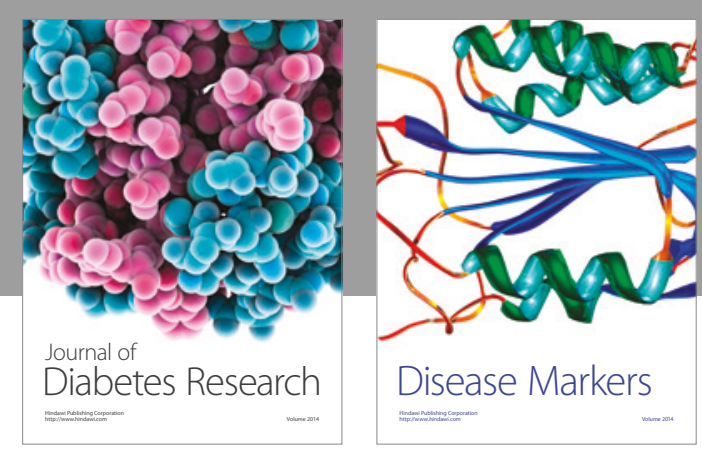

Disease Markers
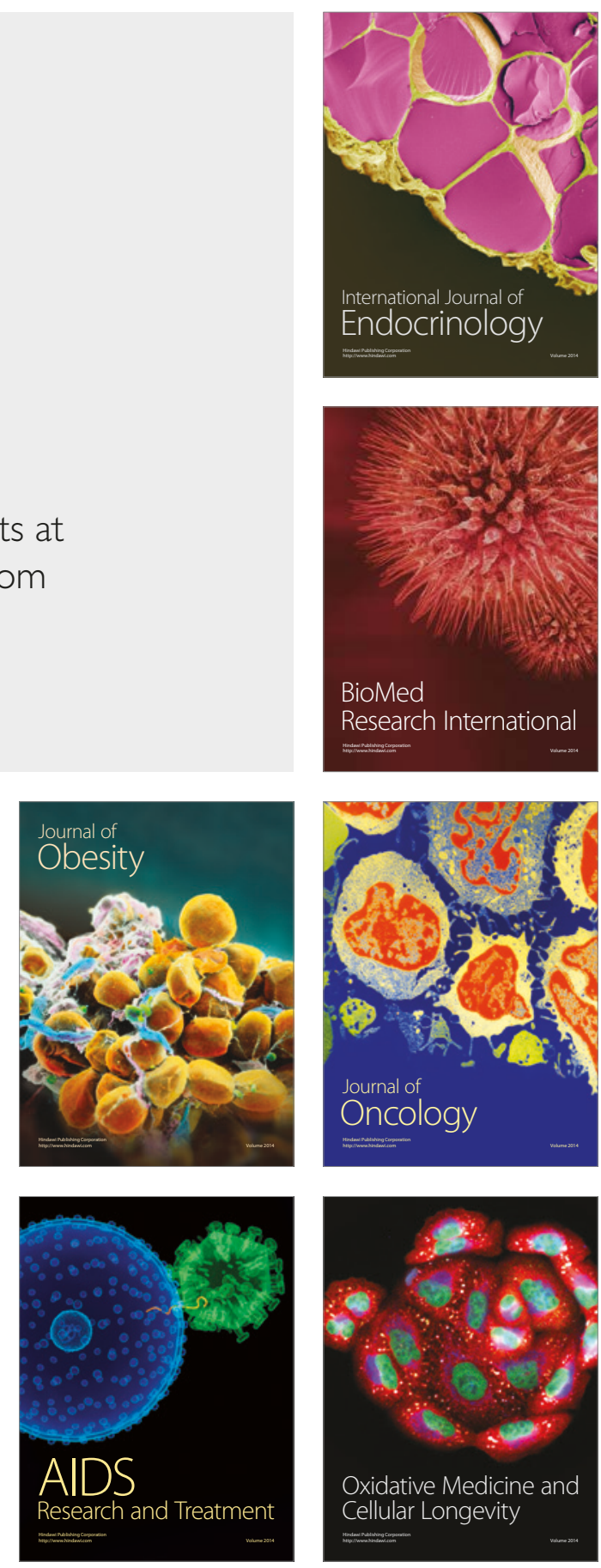